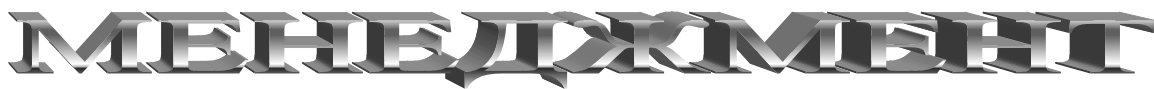

УДК 338.242(075)

DOI: https://doi.org/10.26642/jen-2019-3(89)-71-78

А.Б. Брутман, к.э.н., доц.

Национальньй университет «Запорожская политехника»

С.А. Шпак, к.э.н.

ООО «Рейлтрансхолдинг»

\section{Управленческий потенциал как категория теории управления реструктуризацией промышленных предприятий}

\begin{abstract}
Целью статьи является уточнение содержания понятия «управленческого потенциала предприятия» и его основных составляющих как объектов измерения и управления в задачах управления реструктуризацией промышленных предприятий.

Показано, что понятие «управленческого потенциала предприятия» является естественным обобщением более частных понятий «управленческого потенциала регулярной хозяйственной деятельности» $и$ «управленческого потенциала развития предприятия» как двух его основных составляющих, имеющих самостоятельное значение. В рамках концепции потенциила в экономике как способности $\kappa$ осуществлению имманентно присущей деятельности экономических субъектов понятие представляет собой способность предприятия, характеризующую максимально возможную степень использования экономического потенщиала предприятия и потенциала его развития, определенные без учета управленческого фактора.

Обосновано, что измерение управленческого потенциала предприятия должно базироваться на методах измерения экономического потенциала и потенциала развития предприятия как в полнофакторной, так и частных постановках, а также обеспечивать сопоставление уровней полнофакторных и частных без учета управленческого фактора потенциалов указанных видов.

Ключевые слова: промышленное предприятие; реструктуризаџия; стратегическое управление; управленческий потенциал.
\end{abstract}

Актуальность темы. Экономическая теория потенциалов активно развивается последние два десятилетия преимущество силами ученых стран, образовавшихся в результате распада СССР. Однако, несмотря на значительное число публикаций, ключевые вопросы теории все еще остаются предметом бурных дискуссий, и достижение консенсуса по ним, в силу качественного разнообразия существующих точек зрения и подходов, в ближайшей перспективе весьма проблематично.

К числу недостаточно исследованных вопросов в первую очередь следует отнести выяснение экономического содержания понятия «потенциала в экономике» и формулировку строгого определения данного понятия; выявление экономических объектов, являющихся носителями потенциалов; научную систематизацию всей совокупности потенциалов различных экономических объектов; разработку общей теории измерения потенциалов в экономике.

Среди существующих направлений наиболее последовательной представляется теория потенциалов, основанная на концепции потенциала как специфической способности субъекта экономики, которая характеризует максимально возможные совокупные результаты имманентно присущей данному субъекту деятельности. В рамках такой концепции носителем потенциалов выступает экономический субъект произвольного вида, и основное многообразие потенциалов порождается разнообразием типов экономических субъектов и видов осуществляемой ими деятельности. При этом общепринятая в экономике иерархия (классификация) видов деятельности автоматически предопределяет и соответствующую иерархию потенциалов экономических субъектов.

Актуальность научно обоснованного решения отмеченных выше задач существенно возрастает в рамках концепции управления развитием предприятий на основе управления потенциалами, выдвинутой и развиваемой рядом отечественных ученых. Согласно этой концепции развитие предприятия рассматривается как процесс, обеспечивающий поддержание и/или повышение ключевых потенциалов предприятия. Это ставит перед теорией задачу разработки методов управления потенциалами всех типов, решение которой требует строгого, методологически корректного определения понятия «потенциала» как объекта управления, разработки надежных методов оценки уровня потенциалов и эффективных методов управления потенциалами.

Несмотря на то что, вопросы систематизации существующих разновидностей потенциалов произвольных экономических субъектов и промышленных предприятий в частности еще находятся на стадии исследования, общепринятыми являются представления о том, что управленческий потенциал относится к числу одних из основных потенциалов субъектов экономики нетривиального уровня. Вместе с тем, само понятие «управленческого потенциала» для уровня предприятий в научной экономической

(C) А.Б. Брутман, С.А. Шпак, 2019 
литературе остается практически неопределенным, что исключает возможность научно обоснованной постановки и конструктивного решения задач, связанных с развитием (управлением) управленческого потенциала.

Анализ последних исследований и публикаций. Экономическая теория потенциалов, основанная на концепции потенциала как определенной способности субъектов экономики произвольного иерархического уровня, активно развивается последнее десятилетие в таких трудах ученых-экономистов, как $[1,3,5,7-9,16-20,24,34,35,37]$. В публикациях этих авторов обосновывается необходимость рассмотрения потенциалов в экономике как способности к имманентно присущей субъектам экономики деятельности [16-20], из чего следует, что носителями потенциалов в рамках экономической теории могут выступать только субъекты такой деятельности [15, 37]; дается аргументированная критика альтернативных подходов к определению понятия «потенциала в экономике» $[16,18]$; определяется круг основных задач микроэкономической теории потенциалов, решение которых необходимо для эффективного управления развитием предприятий, среди которых задача систематизации потенциалов является одной из центральных $[1,12,13,19,21]$; выдвигается концепция управления развитием предприятия на основе его потенциалов $[7,14,34,35]$, реализация которой целиком базируется на оценках (измерении) потенциалов [2, 3, 8, 22-24].

Несмотря на то, что практически каждый исследователь в структуре потенциалов предприятия выделяет управленческий (организационно-управленческий) потенциал (см., например, [4, 10, 26, 28]), строгое с методологических позиций определение самого понятия «управленческого потенциала» в научной экономической литературе практически отсутствует, как отсутствуют и попытки его предметного изучения. Активный интерес ученые проявляют к понятию управленческого потенциала лишь применительно к персоналу (см., например, [11, 25, 27, 29, 38, 41, 46, 49] и др.). Так, например, в работах $[40,41,43,44,46,48]$ определяются ключевые особенности управленческой деятельности как разновидности трудовой деятельности, как вид профессиональной деятельности руководителя. В работах $[11,39,42,45,47]$ изучается, как на содержание управленческой детальности влияют современные условия. На соответствующих представлениях основываются и работы, посвященные изучению управленческого потенциала работников $[25,27,29,38,49]$. Однако принципиальные отличия человека и предприятия как субъектов управленческой деятельности и носителей управленческого потенциала не позволяют перенести результаты подобных исследований на уровень предприятий, что особенно наглядно проявляется на примере методов оценки, активизации и развития управленческих способностей персонала.

Возможности уточнения экономического содержания понятия «управленческого потенциала предприятий», методологически строгого определения данного понятия появляются в рамках концепции потенциалов в экономике как определенной способности соответствующих экономических субъектов на пути конкретизации общего понятия потенциала $[16,19,20,37]$ с учетом специфики управленческой деятельности на предприятии.

Цель статьи состоит в исследовании понятия «управленческого потенциала предприятия» как категории теории управления реструктуризацией предприятий, выявлении его взаимосвязи со смежными понятиями данной теории и методологически строгом определении понятия «управленческого потенциала» как объекта количественного измерения и управления.

Изложение основного материала. В соответствии с указанной выше концепцией потенциала как некоторой способности, потенциал в экономике рассматривается как способность экономического субъекта к осуществлению имманентно присущей ему деятельности, отражающая (характеризующая) максимально возможный совокупный результат такой деятельности [16, 17, 37]. Как отмечается в [37], такое определение стало результатом анализа понятия «потенциала», используемого в различных науках, включая физику, механику, биологию, экологию и др., и корректного, т.е. с учетом специфики экономических систем, перенесения общепринятого в механике толкования потенциальной энергии в экономическую среду.

С учетом таких представлений о потенциалах промышленного предприятия рассмотрим содержание понятия «управленческого потенциала».

Как известно, управленческая деятельность является одним из видов регулярной деятельности предприятия, одной из его функций, и поэтому к ней в полной мере применимо понятие «потенциала» как способности предприятия осуществлять такую деятельность. В свете основных положений упомянутой выше теории потенциалов указанная способность должна характеризовать предельные возможности, максимально возможные результаты управленческой деятельности.

В рамках рассмотрения управленческой деятельности предприятия в целом, т.е. как вида деятельности, неделимого на отдельные составляющие, для понимания содержания понятия «управленческого потенциала предприятия» необходимо выяснение того, что считать совокупным (обобщенным) результатом управленческой деятельности, и в каких единицах можно измерить результаты такой деятельности. Актуальность решения этих задач нисколько не снижается с учетом 
видового разнообразия видов деятельности (функций), которые в экономической теории относят к разряду управленческой (это функции планирования, организации, мотивации, контроля и др.), и трудностей при определении единиц измерения результатов управленческой деятельности каждого такого вида.

На верхнем уровне иерархии видов управленческой деятельности в качестве теоретической основы для определения совокупных результатов реализации функции управления предприятия могут выступать следующие положения экономической теории.

Главной целью функционирования предприятия в рыночной экономике является генерирование приемлемого, т.е. на уровне, удовлетворяющем экономические интересы собственников предприятия, чистого дохода (прибыли) на длительной основе.

В процессе функционирования произвольного предприятия можно выделить две основные составляющие: процесс регулярной хозяйственной деятельности и процесс развития. Содержание первого процесса состоит в генерировании чистого дохода (чистой прибыли), содержание второго - в развитии предприятия, т.е. в изменении предприятия с целью обеспечения возможности эффективной реализации первого процесса в будущих, постоянных либо изменяющихся, условиях.

Такому подразделению процесса функционирования предприятия на подпроцессы соответствует и подразделение основных видов деятельности (основных функций) предприятия: функции производства (в широком смысле) или регулярной хозяйственной деятельности и функции развития. В рамках обеих этих функций функция управления является вспомогательной по отношению к указанным основным функциям. Это обстоятельство позволяет рассматривать функцию управления предприятия как функцию, включающую в себя две относительно самостоятельные составляющие: функцию управления регулярной хозяйственной деятельности предприятия и функцию управления развитием предприятия, а также рассматривать категории управленческого потенциала хозяйственной деятельности и управленческого потенциала развития как две относительно самостоятельные категории, подчиненные категории управленческого потенциала предприятия в целом.

Экономический потенциал предприятия представляет собой мгновенную способность генерировать прибыль, т.е. способность, свойственную предприятию в определенный момент времени и в характерных этому моменту времени внешних условиях. Это утверждение заимствовано из [32] с тем лишь уточнением, что из его формулировки исключено указание на уровень прибыли («приемлемую (для собственников) прибыль» в оригинале). Такое уточнение является принципиальным и базируется на результатах исследования, опубликованных в [6].

Потенциал развития представляет собой способность предприятия к структурной адаптации к изменяющимся условиям в пределах характерного времени этого процесса, т.е. способность, интегральную по времени - интервальную способность. Как показано в [33], потенциал развития предопределяет возможности поддержания или повышения экономического потенциала предприятия в изменяющихся условиях функционирования.

Эти положения экономики предприятий и экономической теории потенциалов позволяют подойти к пониманию содержания понятия «управленческого потенциала», выяснению того, что следует рассматривать в качестве совокупного результата управленческой деятельности и ее основных подвидов, а также к выработке базовых методологических положений по измерению управленческого потенциала. Здесь в связи с проблемой определения совокупного результата управленческой деятельности, оценки качества управления и уровня управленческого потенциала будет уместным отметить, что встречающиеся в научной литературе предложения по оценке управленческого потенциала по степени достижения поставленных целей (см., например, [30]) с методологической точки зрения некорректны. Это обусловлено тем, что цели по совершенствованию хозяйственной деятельности или развитию предприятия сами являются одним из (промежуточных) результатов управленческой деятельности, в частности, целеполагания, могут быть неточны либо ошибочны и поэтому не могут служить точкой отсчета для оценки качества управления в целом.

Рассмотрим понятия «управленческого потенциала регулярной хозяйственной деятельности и развития предприятия» более подробно.

Экономический потенциал характеризует предельные возможности по генерированию чистого дохода (его максимально возможную величину) предприятия, находящегося в определенном состоянии и функционирующего в определенных условиях, и его уровень отражает действие всех учитываемых в модели экономического потенциала факторов, включая управленческий фактор. Очевидно, полнофакторная оценка экономического потенциала не может быть выше оценки потенциала без учета качества управления, и лишь при идеальном управлении обе оценки будут совпадать. Это позволяет рассматривать управленческий потенциал регулярной хозяйственной деятельности как способность предприятия, характеризующую его предельные возможности по реализации экономического потенциала предприятия, определенного без учета управленческого фактора. В таком случае в качестве показателей управленческого потенциала регулярной хозяйственной деятельности предприятия могут 
выступать удельные показатели, отражающие степень реализации (использования) указанного выше экономического потенциала.

Такие представления позволяют уточнить и цели управления регулярной хозяйственной деятельности предприятия. Они состоят в обеспечении максимально полной реализации экономического потенциала предприятия с учетом прочих факторов в каждых конкретных условиях.

С другой стороны фактический уровень чистого дохода, полученного предприятием в конкретных условиях функционирования, является совокупным результатом действия всех факторов, определяющих фактическую доходность предприятия, включая и фактор управления. Поэтому сопоставление уровня фактического дохода с уровнем полнофакторного (общего) экономического потенциала позволяет судить об уровне фактического использования экономического потенциала предприятия в целом. Однако вклад управленческого фактора в формирование фактического чистого дохода предприятия, т.е. качество управления, путем сопоставления уровня экономического потенциала в конкретных условиях функционирования, определенного без учета управленческого фактора, с фактически достигнутым уровнем чистого дохода оценить невозможно без знания влияния каждого фактора и произвольной группы факторов на уровень экономического потенциала. Если предположить, что вклад управленческого фактора может быть оценен, то совокупным, обобщенным результатом управленческой деятельности в рамках регулярной или просто хозяйственной деятельности предприятия естественно считать фактически достигнутый уровень реализации (использования) экономического потенциала за вычетом вклада прочих факторов), а в качестве показателей результатов управленческой детальности могут выступать соответствующие удельные показатели, аналогичные, например, показателям использования производственной мощности предприятия.

Таким образом, полнофакторная оценка экономического потенциала, и оценки экономического потенциала без учета фактора управления, управленческого потенциала и фактического совокупного результата управленческой деятельности соотносятся между собой следующим образом:

ЭП $\geq$ ЭП УФ $\geq Ф Р \backslash У Ф \leq Ф Р$,

где ЭП - экономический потенциал предприятия (его оценка);

ЭП\УФ - экономический потенциал без учета управленческого фактора;

ФР\УФ - фактические результаты регулярной хозяйственной деятельности предприятия без учета вклада управленческого фактора;

ФР - фактические результаты.

Из изложенного выше следует, что в рамках таких представлений решение проблемы измерения управленческого потенциала хозяйственной деятельности предприятия всецело обусловлено решением проблемы измерения общего и факторных (о частных, факторных потенциалах см. [31, 36]) экономических потенциалов. При этом решение проблемы выбора показателей единиц измерения управленческого потенциала достаточно очевидно.

По аналогии с управленческим потенциалом регулярной хозяйственной деятельности управленческий потенциал развития предприятия следует рассматривать как способность предприятия реализовать свой потенциал развития. При этом оценки управленческого потенциала развития предприятия, как и оценки управленческого потенциала хозяйственной деятельности, характеризуют степень использования (реализации) потенциала развития.

Таким образом, управленческий потенциал предприятия следует рассматривать как способность обеспечивать достижение главной цели функционирования предприятия, которая обусловлена способностью предприятия использовать текущий экономический потенциал (управленческий потенциал регулярной хозяйственной деятельности) и его способностью реализовывать имеющийся потенциал развития (управленческий потенциал развития предприятия).

Выводы и перспективы дальнейших исследований. Понятие «управленческого потенциала предприятия» как научная категория теории управления остается практически не изученной. В рамках развиваемой авторами настоящего исследования концепции управления развитием промышленных предприятий на основе потенциалов это выступает серьезным препятствием на пути разработки эффективных методов управления реструктуризацией промышленных предприятий.

Согласно представлениям, в соответствии с которыми реструктуризация предприятия рассматривается как процесс поддержания и/или повышения потенциала предприятия в изменяющихся условиях функционирования, оценка уровня потенциалов предприятия (как текущего, так и планируемого) является обязательным условием эффективного управления развитием предприятия. Такая оценка невозможна без четкого определения экономического содержания понятия «управленческого потенциала» как одной из разновидностей потенциала предприятия и выяснение природы управленческого потенциала как объекта измерения и управления.

В развитие экономической теории потенциалов на микроэкономическом уровне и на основе ее ключевого теоретического положения, в соответствии с которым потенциал произвольного экономического субъекта определяется как способность к осуществлению деятельности того или иного 
вида, характеризующая максимально возможные совокупные результаты такой деятельности, управленческий потенциал предприятия в целом в настоящей статье предлагается рассматривать как способность предприятия, характеризующую максимально возможную степень использования экономического потенциала предприятия и потенциала его развития, определенные без учета управленческого фактора. При этом понятие «управленческого потенциала предприятия» естественным образом обобщает более частные понятия «управленческого потенциала регулярной хозяйственной деятельности предприятия» и «управленческого потенциала развития предприятия» как две его составляющие, каждая из которых имеет самостоятельное значение.

Измерение управленческого потенциала предприятия, определенного таким образом, должно базироваться на методах измерения экономического потенциала и потенциала развития предприятия как в полнофакторной, так и частных постановках и обеспечивать сопоставление уровней полнофакторных и частных (без учета управленческого фактора) потенциалов указанных видов.

Разработка таких методов измерения представляет собой одну из наиболее сложных, но чрезвычайно актуальных задач экономической теории потенциалов и теории стратегического управления предприятий в целом, ждущих своего решения.

\section{Список использованной литературы:}

1. Алёхин А.Б. Анализ динамики потенциала предприятий с применением математического моделирования и статистических методов / А.Б. Алёхин, А.Б. Брутман // Вісник ХНУ. Економічні науки. - 2014. - № 3. C. $12-17$.

2. Алёхин А.Б. Обобщенные признаки предприятий, регионов и национальных экономик: проблема измерения и новые подходы / А.Б. Алёхин // Економіст. - 2011. - № 8. - С. 24-29.

3. Алёхин А.Б. Сравнительный анализ функционального и оптимизационного подходов к оценке экономического потенциала предприятий / А.Б. Алёхин, Н.Н. Ванина // Вісник ХНУ. Економічні науки. -2014. - № 2. - С. 14-19.

4. Бачевський Б.С. Потенціал і розвиток підприємства : навчальний посібник / Б.С. Бачевський, I.В. Заблодська, О.О. Решетняк. - К. : Центр учбової літератури, 2009. - 400 с.

5. Брутман А.Б. Измерение конкурентоспособности промышленных предприятий на основе оценки их производственного потенциала / А.Б. Брутман // Вісник ХНУ. Економічні науки. - 2010. - № 4. - С. 136-141.

6. Брутман А.Б. Категория конкурентоспособности как обобщение понятия экономического потенциала предприятия / А.Б. Брутман // Бизнес Информ. - 2018. - № 2. - С. 127-134.

7. Брутман А.Б. Конкурентоспособность предприятий: оценка на основе их потенциалов : монография / А.Б. Брутман. - Запорожье : ООО «ЛИПС» ЛТД, 2012. - 220 с.

8. Диленко В.А. Математические модели формирования и анализа экономического потенциала / В.А. Диленко, $O . B$. Захарова // Проблемы развития внешнеэкономических связей и привлечения иностранных инвестиций: региональный аспект : сб. науч. тр. : статьи. - Донецк, 2009. - С. 202-208.

9. Диленко В.А. Экономико-математическое моделирование инновационных процессов / В.А. Диленко. - Одесса : Фенікс, 2012. - 344 с

10. Потенціал підприємства: формування та оцінка : навчальний посібник / О.К. Добикіна, В.С. Рижиков, С.В. Касьянюк та ін. - К. : Центр учбової літератури, 2007. - 208 с.

11. Гидденс Э. Последствия современности / Э.Гидденс; пер. с англ. Т.А. Дмитриева. - М. : Праксис, 2011. -354 с

12. Карапейчик И.Н. Классификации потенциалов в экономике: критический взгляд / И.Н. Карапейчик // Вісник ХНУ. Економічні науки. - 2012. - № 2. - С. 116-125.

13. Карапейчик И.Н. Классификация потенциалов экономических субъектов: методологические аспекты и возможные решения / И.Н. Карапейчик // Актуальні проблеми економіки. - 2013. - № 1 (139). - С. 20 -31.

14. Карапейчик И.Н. Логика использования потенциалов в задачах управления предприятием / И.Н. Карапейчик // Бизнес Информ. - 2012. - № 9. - С. 285-290.

15. Карапейчик И.Н. Носители потенциалов в экономической теории / И.Н. Карапейчик // Ефективна економіка. - 2012. - № 8 [Электронный ресурс]. - Режим доступа : http://www.economy.nayka.com.ua/index.php?operation=1\&iid=1324.

16. Карапейчик И.Н. О сущности и соотношении понятий экономического и производственного потенциалов / И.Н. Карапейчик // Бизнес Информ. - 2012. - № 3. - С. 8-12.

17. Карапейчик И.Н. О сущности и соотношении понятий экономического и производственного потенциалов / И.Н. Карапейчик // Бизнес Информ. - 2012. - № 4. - С. 10-13.

18. Карапейчик И.Н. Оценка инновационного потенциала машиностроительных предприятий И.Н. Карапейчик. - Мариуполь : Новый мир, 2011. - 184 с.

19. Карапейчик И.Н. Понятие потенциала в экономике: задачи и направления исследований / И.Н. Карапейчик // Актуальні проблеми економіки. - 2012. - № 7 (133). - С. 16-25.

20. Карапейчик И.Н. Понятие потенциала в экономике: общая концепция / И.Н. Карапейчик // Ефективна економіка. - 2011. - № 12 [Электронный ресурс]. - Режим доступа : http://www.economy.nayka.com.ua/index.php?op=1\&z=820.

21. Карапейчик И.Н. Потенциальные функции и задача систематизации потенциалов в экономике / И.Н. Карапейчик // Інноваційні економіка. - 2012. - № 4 (30). - С. 9-15.

22. Карапейчик И.Н. Ресурсно-факторная концепция потенциалов: объект и методология оценки / И.Н. Карапейчик // Современный научный вестник. - 2013. - № 23 (162). - С. 11-20. 
23. Карапейчик И.Н. Ресурсно-факторный подход к оценке потенциалов с позиций квалиметрии И.Н. Карапейчик // Україна наукова : міжнар. наук.-практ. конф. : тези допов. - К., 2013. - Ч. 1. - С. 32-39.

24. Карапейчик И.Н. Факторный и системный подходы к измерению потенциалов предприятий: сравнительный модельный анализ / И.Н. Карапейчик // Уральский научный вестник. - 2013. - № 15 (63). - С. 100-117.

25. Кибанов А.Я. Управление персоналом организации / А.Я. Кибанов. - М. : ИНФРА-М, 2015. - 365 с.

26. Краснокутська Н.В. Потенціал підприємства: формування та оцінка / Н.В. Краснокутська. - К. : Центр навчальної літератури, 2005. - $352 \mathrm{c}$.

27. Кудрявцева Е.И. Управленческий потенциал персонала: функции против институций / Е.И. Кудрявцева. СПб : Социально-гуманитарное знание, 2015. - 196 с.

28. Лапин Е.В. Экономический потенциал предприятия / E.B. Лапин. - Сумы : ИТД «Университетская книга», 2002. $-310 \mathrm{c}$.

29. Рысина В.Н. Развитие кадрового потенциала системы управления / В.Н. Рысина. - М. : ЮНИТИДАНА, 2002. - $326 \mathrm{c}$.

30. Фаткин Л.В. Развитие управленческого потенциала промышленных предприятий / Л.В. Фаткин, Д.С. Петросян // Аудит и финансовый анализ. - 2012. - № 3. - С. 354-360.

31. Шпак С.А. Информационная наполненность оценок факторных потенциалов и потенциальных функций промышленного предприятия / С.A. Шпак // ВісникХНУ. Економічні науки. - 2018. - № 3.- С. 32-49.

32. Шиак С.A. О временной природе конкурентоспособности, экономического потенциала и потенциала развития / С.A. Шпак // Вісник Національного технічного університету «Харківський політехнічний інститут» (економічні науки). - 2018. - № 19. - С. 11-18.

33. Шnак С.A. Потенциал развития в системе потенциалов промышленного предприятия / C.A. Шnaк // Проблеми економіки. - 2018. - № 1 (35). - С. 280-286.

34. Шиак C.A. Потенциалы как объекты стратегического управления развитием промышленных предприятиями / С.A. Шпак // ВісникХНУ. Економічні науки. - 2017. - № 4. - С. 238-245.

35. Шиак C.A. Теоретические основания стратегического управления реструктуризацией предприятий на основе потенциалов / С.А. Шиак // Бизнес Информ. - 2017. - № 4. - С. 347-356.

36. Шиак С.A. Факторные потенциалы промышленного предприятия и их разновидности / C.A. Шnак // Уральский научный вестник. - 2018. - № 5 (170). - С. 21-42.

37. Alyokhin A.B. Economic theory of potential. Quasi axiomatic approach to modeling and measurement / A.B. Alyokhin, A.B. Brutman // Вісник ХНУ. Економічні науки. - 2015. - № 3. - С. 91-105.

38. Drucker P. Management challenge for XXI century / P.Drucker. - NY : Harper Business Press, 2001. -224 p.

39. Farkas M.F. Knowledge workers, competencies, virtuality and management / M.F. Farkas, L.G. Török // Polish journal of management studies. - 2011. - Vol. 4. - P. 67-76.

40. Flanagan J.C. The critical incident technique / J.C. Flanagan // Psychological Bulletin. - 1954 . № 51. - P. 327-349.

41. Hodgkinson G.Ph. The Competent Organization: A Psychological Analysis of the Strategic Management Process (Managing Work and Organizations) / G.Ph. Hodgkinson, P.R. Sparrow. - Philadelphia : Open University Press, 2002. - $432 \mathrm{p}$.

42. Kahai S.S. Effects of leadership style and anonymity on the discussion of an ethical issue in an electronic meeting system context / S.S. Kahai, B.J. Avolio, S.Weisband (ed.) // Leadership at a distance: Research in technologically supported work. - NJ : Lawrence Erlbaum Associates, 2008. - P. 513-538.

43. Koontz H. Management / H.Koontz, H.Weihrieh; 10-th ed. - NY : MeGraw-Hill Inc., 1995. - 685 p.

44. Kotter J. Leading change: why transformation efforts fail / J.Kotter // Harvard Business Review. - 1995. - Vol. 73. P. 59-68.

45. National systems of production, innovation and competence building / B.A. Lundvall, B.Johnson, E.S. Andersen, B.Dalum // Research Policy. - 2002. - № 31. - P. 213-231.

46. Mintzberg H. The Manager's job: Folklore and Fact / H.Mintzberg // Harvard Business Review. - 1975. - Vol. 53. P. 49-61.

47. Phaal R. Technology Roadmapping: linking technology resources to business objectives / R.Phaal, C.Farrukh, D.Probert. - Cambridge : Centre for Technology Management, University of Cambridge, 2001. - $18 \mathrm{p}$.

48. Development and content validation of a «hyperdimensional" taxonomy of managerial competence / R.P. Tett, H.A. Guterman, A.Bleier, P.J. Murphy // Human Performance. - 2000. - № 13. - P. 205-251.

49. Weiner I.B. Handbook on psychology, industrial and organizational psychology / I.B. Weiner, N.W. Schmitt, S.Highhouse // The psychology of work. - NY : McGraw Hill, 2012. - Vol. 12. - 816 p.

\section{References:}

1. Alekhin, A.B. and Brutman, A.B. (2014), «Analiz dinamiki potentsiala predpriyatiy s primeneniem matematicheskogo modelirovaniya i statisticheskikh metodov», Visnyk HNU, Ekonomichni nauky, No. 3, pp. 12-17.

2. Alekhin, A.B. (2011), «Obobshchennye priznaki predpriyatiy, regionov i natsional'nykh ekonomik: problema izmereniya i novye podkhody», Ekonomist, No. 8, pp 24-29.

3. Alekhin, A.B. and Vanina, N.N. (2014), «Sravnitel'nyy analiz funktsional'nogo i optimizatsionnogo podkhodov k otsenke ekonomicheskogo potentsiala predpriyatiy», Visnyk HNU, Ekonomichni nauky, No. 2, pp. 14-19.

4. Bachevs'kyj, B.Je., Zablods'ka, I.V. and Reshetnjak, O.O. (2009), Potencial i rozvytok pidpryjemstva, navchal'nyj posibnyk, Centr uchbovoi' literatury, K., 400 p.

5. Brutman, A.B. (2010), «Izmerenie konkurentosposobnosti promyshlennykh predpriyatiy na osnove otsenki ikh proizvodstvennogo potentsiala», Visnyk HNU, Ekonomichni nauky, No. 4, pp. 136-141.

6. Brutman, A.B. (2018), «Kategoriya konkurentosposobnosti kak obobshchenie ponyatiya ekonomicheskogo 
potentsiala predpriyatiya», Biznes Inform, No. 2, pp. 127-134.

7. Brutman, A.B. (2012), Konkurentosposobnost' predpriyatiy: otsenka na osnove ikh potentsialov, monografiya, OOO «LIPS» LTD, Zaporozh'e, 220 p.

8. Dilenko, V.A. and Zakharova, O.V. (2009), «Matematicheskie modeli formirovaniya i analiza ekonomicheskogo potentsiala» Problemy razvitiya vneshneekonomicheskikh svyazey i privlecheniya inostrannykh investitsiy: regional'nyy aspekt, sb. nauch. tr., stat'i, Donetsk, pp. 202-208.

9. Dilenko, V.A. (2012), Ekonomiko-matematicheskoe modelirovanie innovatsionnykh protsessov, Feniks, Odessa, 344 p.

10. Dobykina, O.K., Ryzhykov, V.S., Kas'janjuk, S.V. and other (2007), Potencial pidpryjemstva: formuvannja ta ocinka, navchal'nyj posibnyk, Centr uchbovoi' literatury, K., 208 p.

11. Giddens, E. (2011), Posledstviya sovremennosti, Translated by Dmitrieva, T.A., Praksis, M., 354 p.

12. Karapeychik, I.N. (2012), «Klassifikatsii potentsialov v ekonomike: kriticheskiy vzglyad», Visnyk HNU, Ekonomichni nauky, No. 2, pp. 116-125.

13. Karapeychik, I.N. (2013), «Klassifikatsiya potentsialov ekonomicheskikh sub"ektov: metodologicheskie aspekty i vozmozhnye resheniya», Aktual'ni problemy ekonomiky, No. 1 (139), pp. 20-31.

14. Karapejchik, I.N. (2012), «Logika ispol'zovanija potencialov v zadachah upravlenija predprijatiem», Biznes Inform, No. 9, pp. 285-290.

15. Karapeychik, I.N. (2012), «Nositeli potentsialov v ekonomicheskoy teorii», Efektyvna ekonomika, No. 8, [Online], available at: $\mathrm{http} / / / \mathrm{www}$. economy.nayka.com.ua/index.php?operation=1\&iid=1324

16. Karapeychik, I.N. (2012), «O sushchnosti i sootnoshenii ponyatiy ekonomicheskogo i proizvodstvennogo potentsialov», Biznes Inform, No. 3, pp. 8-12.

17. Karapeychik, I.N. (2012), «O sushchnosti i sootnoshenii ponyatiy ekonomicheskogo i proizvodstvennogo potentsialov», Biznes Inform, No. 4, pp. 10-13.

18. Karapeychik, I.N. (2011), Otsenka innovatsionnogo potentsiala mashinostroitel'nykh predpriyatiy, «Novyy mir», Mariupol', $184 \mathrm{p}$.

19. Karapeychik, I.N. (2012), «Ponyatie potentsiala v ekonomike: zadachi i napravleniya issledovaniy», Aktual'ni problemy ekonomiky, No. 7 (133), pp.16-25.

20. Karapeychik, I.N. (2011), «Ponyatie potentsiala v ekonomike: obshchaya kontseptsiya», Efektyvna ekonomika, No. 12, [Online], available at: http://www.economy.nayka.com.ua/index.php?op=1\&z=820

21. Karapeychik, I.N. (2012), «Potentsial'nye funktsii i zadacha sistematizatsii potentsialov v ekonomike», Innovacijna ekonomika, No. 4 (30), pp. 9-15.

22. Karapeychik, I.N. (2013), «Resursno-faktornaya kontseptsiya potentsialov: ob"ekt i metodologiya otsenki», Sovremennyy nauchnyy vestnik, No. 23 (162), pp. 11-20.

23. Karapeychik, I.N. (2013), «Resursno-faktornyy podkhod k otsenke potentsialov s pozitsiy kvalimetrii», Ukrai'na naukova, mizhnar. nauk.-prakt. konf., tez. dopov, Kyi'v, Vol. 1, pp. 32-39.

24. Karapeychik, I.N. (2013), «Faktornyi i sistemnyi podkhody k izmereniyu potentsialov predpriyatii: sravnitel'nyi model'nyi analiz», Ural'skiy nauchnyy vestnik, No. 15 (63), pp. 100-117.

25. Kibanov, A.Ya. (2015), Upravlenie personalom organizatsii, INFRA-M, M., 365 p.

26. Krasnokuts'ka, N.V. (2005), Potencial pidpryjemstva: formuvannja ta ocinka, Centr navchal'noi' literatury, K., 352 p.

27. Kudryavtseva, E.I. (2015), Upravlencheskiy potentsial personala: funktsii protiv institutsiy, Sotsial'nogumanitarnoe znanie, $\mathrm{SPb}, 196 \mathrm{p}$.

28. Lapin, E.V. (2002), Ekonomicheskiy potentsial predpriyatiya, ITD «Universitetskaya kniga», Sumy, 310 p.

29. Rysina, V.N. (2002), Razvitie kadrovogo potentsiala sistemy upravleniya, YuNITI-DANA, M., 326 p.

30. Fatkin, L.V. and Petrosyan, D.S. (2012), «Razvitie upravlencheskogo potentsiala promyshlennykh predpriyatiy», Audit i finansovyy analiz, No. 3, pp. 354-360.

31. Shpak, S.A. (2018), «Informatsionnaya napolnennost' otsenok faktornykh potentsialov i potentsial'nykh funktsiy promyshlennogo predpriyatiya», Visnyk HNU, Ekonomichni nauky, No. 3, pp. 32-49.

32. Shpak, S.A. (2018), «O vremennoy prirode konkurentosposobnosti, ekonomicheskogo potentsiala i potentsiala razvitiya», Visnyk Nacional'nogo tehnichnogo universytetu "Harkivs'kyj politehnichnyj instytut» (ekonomichni nauky), No. 19, pp. 11-18.

33. Shpak, S.A. (2018), «Potentsial razvitiya v sisteme potentsialov promyshlennogo predpriyatiya», Problemy ekonomiky, No. 1 (35), pp. 280-286.

34. Shpak, S.A. (2017), «Potentsialy kak ob"ekty strategicheskogo upravleniya razvitiem promyshlennykh predpriyatiyami», Visnyk HNU, Ekonomichni nauky, No. 4, pp. 238-245.

35. Shpak, S.A. (2017), «Teoreticheskie osnovaniya strategicheskogo upravleniya restrukturizatsiey predpriyatiy na osnove potentsialov», Biznes Inform, No. 4, pp. 347-356.

36. Shpak, S.A. (2018), «Faktornye potentsialy promyshlennogo predpriyatiya i ikh raznovidnosti», Ural'skiy nauchnyy vestnik, No. 5 (170), pp. 21-42.

37. Alyokhin, A.B. and Brutman, A.B. (2015), «Economic theory of potential. Quasi axiomatic approach to modeling and measurement», Visnyk HNU, Ekonomichni nauky, No. 3, pp. 91-105.

38. Drucker, P. (2001), Management challenge for XXI century, Harper Business Press, NY, 224 p.

39. Farkas, M.F. and Török, L.G. (2011), «Knowledge workers, competencies, virtuality and management», Polish journal of management studies, Vol. 4, pp. 67-76.

40. Flanagan, J.C. (1954), «The critical incident technique», Psychological Bulletin, No. 51, pp. 327-349.

41. Hodgkinson, G.Ph. and Sparrow, P.R. (2002), The Competent Organization: A Psychological Analysis of the Strategic Management Process (Managing Work and Organizations), Open University Press, Philadelphia, $432 \mathrm{p}$.

42. Kahai, S.S. and Avolio, B.J. (2008), «Effects of leadership style and anonymity on the discussion of an ethical issue in an electronic meeting system context», in Weisband, S. (ed.), Leadership at a distance: Research in 
technologically supported work, Lawrence Erlbaum Associates, NJ, pp. 513-538.

43. Koontz, H. and Weihrieh, H. (1995), Management, 10-th ed., MeGraw-HilI Inc., NY, 685 p.

44. Kotter, J. (1995), «Leading change: why transformation efforts fail», Harvard Business Review, Vol. 73, pp. 59-68.

45. Lundvall, B.A., Johnson, B., Andersen, E.S. and Dalum, B. (2002), «National systems of production, innovation and competence building», Research Policy, No. 31, pp. 213-231.

46. Mintzberg, H. (1975), «The Manager's job: Folklore and Fact», Harvard Business Review, Vol. 53, pp. $49-61$.

47. Phaal, R., Farrukh, C. and Probert, D. (2001), Technology Roadmapping: linking technology resources to business objectives, Centre for Technology Management, University of Cambridge, Cambridge, $18 \mathrm{p}$.

48. Tett, R.P., Guterman, H.A., Bleier, A. and Murphy, P.J. (2000), «Development and content validation of a «hyperdimensional" taxonomy of managerial competence», Human Performance, No. 13, pp. 205-251.

49. Weiner, I.B., Schmitt, N.W. and Highhouse, S. (2012), «Handbook on psychology, industrial and organizational psychology», The psychology of work, McGraw Hill, NY, Vol. 12, 816 p.

Брутман Анна Богданівна - кандидат економічних наук, доцент, завідувач кафедри іноземних мов професійного спілкування Національного універсітету «Запорізька політехника».

Наукові інтереси:

- $\quad$ теоретичні та методичні засади оцінки конкурентоспроможності промислових підприємств;

- теоретичні та методичні аспекти конкурентних зіставлень;

- методика викладання ділової іноземной мови (англ.) та іноземної мови (англ.) професийного спілкування (економіка підприємства, комерційна діяльність).

Шпак Сергій Олександрович - кандидат економічних наук, провідний фахівець з функціональновартісного аналізу, ТОВ «РЕЙЛТРАНСХОЛДІНГ» м. Маріуполь

Наукові інтереси:

- теоретичні та методичні засади стратегічного управління реструктуризацією промислових підприємств.

Стаття надійшла до редакції 25.06.2019. 